\title{
VISZAPP - a tool for rapid patient urgency assessment, admission, and care monitoring and evaluation in emergency departments
}

\author{
Lykke Burmølle Andersen
}

From Danish Society for Emergency Medicine: Research Symposium 2010

Roskilde, Denmark. 20-21 May 2010

\section{Background}

In 2010 the Danish emergency departments will be fewer, but larger which leads to an increase of patients within the units. This induces logistic challenges and demands considerable resources. For instance the phenomenon of "over-crowding" in the emergency room may occur, where a large number of patients blur the clinician's overview and increases the risk of overlooking patients requiring immediate attention.

In cooperation with the regional hospitals in Viborg, Silkeborg and Skive Logica has developed and implemented VISZAPP(Visitation Zap Application). VISZAPP is a tool for assessing the need for care and prioritizing patients even before actually arriving to the emergency departments.

\section{Methods}

A specialised integration engine for healthcare is used to retrieve data (Patient data, initial complaint, trauma data, physiological parameters and a triage score) in a web based application, integrate the data into the hospitals EHR and PAS system and present the data on both $\mathrm{PC}$ and 42 inch electronic boards on different locations in the emergency reception areas.

\section{Results}

All relevant data are saved electronically. There is no double-registration. No incoming patients are left "unknown". Specialised paramedic teams are standing by when the patients enter the emergency departments. The administrative work is reduced by $80 \%$. The clinical condition of all incoming patients is assessed according

\footnotetext{
Correspondence: lykke.burmolle.andersen@logica.com
} Logica Denmark A/S, 8000 Aarhus C, Denmark to an evidence based triage model (ADAPT). No cases of "over-crowding" in the emergency departments.

\section{Conclusion}

Viszapp was implemented 23rd March 2010. That is why it is not yet possible to conclude whether or not the capability of "knowing" the clinical condition of the patients before arrival to the emergency departments has given a significant difference to patient health outcomes. However, the system facilitates the initiation of further assessment, documentation of patients and is an effective tool for department organisation, monitoring and evaluation.

Published: 17 September 2010

doi:10.1186/1757-7241-18-S1-P40

Cite this article as: Andersen: VISZAPP - a tool for rapid patient urgency assessment, admission, and care monitoring and evaluation in emergency departments. Scandinavian Journal of Trauma, Resuscitation and Emergency Medicine 2010 18(Suppl 1):P40.

Submit your next manuscript to BioMed Central and take full advantage of:

- Convenient online submission

- Thorough peer review

- No space constraints or color figure charges

- Immediate publication on acceptance

- Inclusion in PubMed, CAS, Scopus and Google Scholar

- Research which is freely available for redistribution

Submit your manuscript at www biomedcentral.com/submit
Biomed Central 